\title{
Pelayanan Terhadap Penyandang Disabilitas UPTD Balai Rehabilitasi Terpadu Penyandang Disabilitas Dinas Sosial DIY Tahun 2017-2019
}

\author{
Davinia Farah Salwahanan ${ }^{1}$, Ane Permatasari ${ }^{2}$ \\ ${ }^{1}$ Universitas Muhammadiyah Yogyakarta, Bantul, Yogyakarta, Indonesia \\ ${ }^{2}$ Universitas Muhammadiyah Yogyakarta, Bantul, Yogyakarta, Indonesia
}

\section{ARTICLE INFORMATION}

Received: July 17, 2020

Revised: October 29, 2020

Accepted: November 01, 2020

Available online: November 13, 2020

\section{KEYWORDS}

Public Service, Disabilities, Regulation

CORRESPONDENCE

Phone: +6285801644583

E-mail: daviniasalwahananl@gmail.com

\section{A B S T R A C T}

The Integrated Rehabilitation of Persons with Disabilities of the DIY Social Service is to provide a livelihood and a decent life for the disabled. The discussion of the diffable is felt to be very isolating the movement of the diffable to access public services especially in public. The granting of rights for persons with disabilities has been regulated in Law Number 8 of 2016 concerning Persons with Disabilities and regulated in DIY Regulation Number 4 of 2012 governing the protection and fulfillment of the rights of persons with disabilities. The results of the study showed that the services provided at the UPTD Integrated Rehabilitation Center for Persons with Disabilities of the Social Service DIY provided a one-stop service. This can be a place for people with disabilities to channel their talents in Vocational Guidance and can improve themselves so that they can be social like the general public.

\section{PENDAHULUAN}

Undang-Undang Nomor 8 Tahun 2016 tentang Penyandang Disabilitas merupakan dasar hukum untuk dijadikan tolak ukur dalam pelaksanaan pemenuhan hak bagi penyandang disabilitas, diantaranya ialah hak dibidang pendidikan, kesehatan, ekonomi, politik, budaya serta hak hidup secara mandiri (Halalia, 2017; Indriyany, 2015). Jauh sebelum disahkannya payung hukum negara bagi penyandang disabilitas yaitu Undang-Undang Nomor 8 Tahun 2016, Pemda Daerah Istimewa Yogyakarta melalui Perda DIY Nomor 4 Tahun 2012 telah mengatur tentang perlindungan dan pemenuhan hak-hak penyandang disabilitas. Melalui Perda DIY Nomor 4 Tahun 2012 dapat dijadikan perlindungan hukum bagi penyandang disabilitas yang berdomisili di DIY (Mumpuni $\&$ Zainudin, 2017; Yunizar, 2015).

Pemda Daerah Istimewa Yogyakarta melalui Perda Nomor 4 Tahun 2012 telah menjamin perlindungan dan pemenuhan hakhak bagi penyandang disabilitas. Melalui Dinas Sosial, pemerintah DIY menyelenggarakan rehabilitasi sosial dan pelatihan keterampilan bagi penyandang disabilitas yang bertempat di Balai Rehabilitasi Terpadu Penyandang Disabilitas (Balai RTPD) yang sebelumnya bernama Pusat Rehabilitasi Terpadu Penyandang Cacat (PRTPC) mempunyai fungsi pelayanan terpadu yaitu, rehabilitasi sosial, medis, dan vokasional (Dewi, 2015; Pratomo, 2015). Sebagai lembaga yang menangani permasalahan sosial, Balai Rehabilitasi Terpadu
Penyandang Disabilitas Dinas Sosial Pemprov Daerah Istimewa Yogyakarta memiliki peran penting dalam hal rehabilitasi dan pemberdayaan penyandang disabilitas yang ada di Daerah Istimewa Yogyakarta. Selain itu, bentuk pelayanan di Balai RTPD Yogyakarta menerapkan model pelayanan satu (1) pintu dan keuntungan dari model ini hanya diterapkan di 2 negara yaitu Indonesia dan Singapura, penerapan di Indonesia hanya dilakukan di Balai Rehabilitasi Terpadu Penyandang Disabilitas. Adapun tujuan dari rehabilitas itu sendiri bertujuan untuk mengembalikan fungsi sosialnya (Holle, 2011; Thohari, 2014). Sedangkan pemberdayaan dalam segi hal pengembangan keterampilan, potensi, serta bakat diri seseorang sebagai modal untuk bersaing dengan orang banyak dalam hal memperoleh pekerjaan (Andayani \& Afandi, 2016; Tanjung, 2018).

Data Dinas Sosial DIY dalam dokumen PPID Dinas Sosial DIY (DIY, 2018) menyebutkan bahwa jumlah penyandang disabilitas DIY berjumlah 27.094 dengan sebaran lima (5) Kabupaten/Kota di DIY yaitu Bantul (6324); Gunung Kidul (7694); Kulon Progo (5208); Sleman (6079); dan Kotamadya (1789). Data tersebut merupakan jumlah penyandang disabilitas yang terangkum dari semua jenis atau ragam disabilitas di DIY. Dari data tersebut dapat diklasifikasikan dalam kategori disabilitas dan jenis yang dialami setiap Kabupaten/Kota di DIY sebagaimana berikut disajikan dalam tabel 1. 
Tabel 1. Kategori Usia Penyandang Disabilitas

\begin{tabular}{|c|c|c|c|c|c|c|c|c|}
\hline \multirow[b]{2}{*}{ No } & \multicolumn{2}{|c|}{ PMKS } & \multicolumn{5}{|c|}{ Kabupaten Kota } & \multirow[b]{2}{*}{ Jumlah } \\
\hline & Kategori & Jenis Distabilitas & $\begin{array}{l}\text { Kulon } \\
\text { Progo }\end{array}$ & Bantul & $\begin{array}{c}\text { Gunung } \\
\text { Kidul }\end{array}$ & Sleman & Yogyakarta & \\
\hline 1 & Mental & Psikotik & 368 & 436 & 172 & 390 & 269 & 1.635 \\
\hline 2 & Sensorik & Netra & 366 & 464 & 709 & 366 & 110 & 2.015 \\
\hline \multirow{6}{*}{3} & \multirow{6}{*}{ Fisik } & Runguwicara & 391 & 437 & 638 & 418 & 112 & 1.996 \\
\hline & & Eks Kronis & 199 & 176 & 328 & 212 & 160 & 1.075 \\
\hline & & Tubuh Kaki & 1.023 & 958 & 1.223 & 751 & 250 & 4.205 \\
\hline & & Tubuh Tangan & 284 & 370 & 594 & 205 & 75 & 1.528 \\
\hline & & Tubuh Bungkuk & 162 & 186 & 251 & 102 & 31 & 732 \\
\hline & & Tubuh Kerdil & 27 & 73 & 87 & 35 & 12 & 234 \\
\hline 4 & Intelektual & Mental Retardasi & 1.438 & 1.771 & 1.888 & 1.591 & 465 & 7.153 \\
\hline 5 & Ganda & Ganda & 233 & 427 & 431 & 232 & 67 & 1.390 \\
\hline \multirow[t]{2}{*}{6} & $\begin{array}{c}\text { Tidak } \\
\text { Diketahui } \\
\text { Jenis } \\
\text { Kecacatan }\end{array}$ & \multirow[t]{2}{*}{ N/A } & 717 & 1.026 & 1.373 & 1.777 & 238 & 5.131 \\
\hline & Jumlah & & 5.208 & 6.324 & 7.694 & 6.079 & 1.789 & 27.094 \\
\hline
\end{tabular}

Sumber: http://dinsos.jogjaprov.go.id

Melihat permasalahan pemenuhan hak difabel dan tingginya angka penyandang disabilitas khususnya di DIY, menarik untuk membahas bagaimana pelayanan yang diberikan Balai Rehabilitasi Terpadu Penyandang Disabilitas guna mengembangkan potensi diri dan menngoptimalkan pemberdayaan penyandang disabilitas dalam hal memperoleh hak yang sama pada umumnya. Jika pelayanan yang diberikan dirasa kurang baik maka bisa dijadikan evaluasi bagi pemangku kebijakan untuk memperbaiki sistem pelayanan bagi penyandang disabilitas. Namun sebaliknya, jika pelayanan yang diberikan kepada penyandang disabilitas sudah memenuhi standar pelayanan maka dapat diciptakan inovasi, ide, dan gagasan baru untuk variasi pelayanan agar pelayanan yang diberikan dapat memberikan dampak positif bagi kehidupan klien di masa depan. Selain itu, menjalankan suatu pelayanan akan memunculkan eberapa faktor penghambat dan pendukung pelayanan yang manakala dapat dijadikan koreksi dan inovasi bagi penyedia pelayanan untuk menciptakan pelayanan yang sesuai dengan keadaan

\section{METODE}

Dalam penulisan jurnal ini penulis menerapkan metode penelitian deskriptif kualitatif, yaitu penelitian yang dilakukan untuk memahami keadaan yang dialami secara langsung oleh pelaku atau sasaran penelitian (Sugiyono, 2009). Penulis berusaha mendeskripsikan data-data yang diperoleh di lapangan secera detail sesuai dengan informasi yang didapatkan dari pelaku berjumlah 20 orang yang terdiri dari : kepala dinas, kepala TU, pekerja sosial (2), tenaga medis (3), terapis (2), pekerja vokasional (7), warga binaan (4). Hasil penelitian diperkuat dengan sumber-sumber lainnya. Sehingga dapat ditarik kesimpulan yang benar sebagai jawaban atas permasalahan tentang Pelayanan Terhadap Penyandang Disabilitas UPTD Balai Rehabilitasi Terpadu Penyandang Disabilitas Dinas Sosial DIY Tahun 2017-2019.

Selanjutnya, menurut Sugiono (2012) dalam mengartikan penelitian kualitatif menggunakan teknik purposive sampling dan snowball sampling. Teknik purposive sampling merupakan teknik pengambilan data atau sampel dengan mempertimbangkan pengambilan responden yang paling mengerti terkait data yang dibutuhkan peneliti. Selanjutnya teknik snowball sampling yaitu pengambilan sampel yang berawal sedikit lalu lama-lama menjadi berkembang (Sugiyono, 2012)

\section{HASIL DAN PEMBAHASAN Rehabilitasi Sosial}

Rehabilitasi sosial merupakan pelayanan utama sebagai dasar pelayanan untuk mengetahui tingkatan sosial dalam diri warga binaan. Menurut Undang-Undang Nomor 11 Tahun 2009 tentang Kesejahteraan sosial yaitu, "Proses refungsionalisasi dan pengembangan untuk memungkinkan seseorang mampu melaksanakan fungsi sosialnya secara wajar dalam kehidupan bermasyarakat". Rehabilitasi sosial bertujuan untuk mengembalikan dan meningkatkan fungsi sosialnya karena pada umumnya latar belakang dari penyandang disabilitas yaitu memiliki rasa kepercayaan diri yang kurang. Setelah mengikuti rehabilitasi sosial diharapkan kedepannya warga binaan mampu menjalankan fungsi sosialnya ditengah-tengah masyarakat seperti orang tanpa kekurangan apapun atau nondisabilitas (Tanjung, 2018). Berikut disajikan tabel 2 tentang data pelaksanaan rehabilitasi sosail.

Tabel 2. Data Pelaksanaan Rehabilitasi Sosial

\begin{tabular}{lll}
\hline No & \multicolumn{1}{c}{ Point } & \multicolumn{1}{c}{ Uraian } \\
\hline 1. & Pekerja & a. Pekerja Sosial $: 5$ orang \\
& & b. Pramu Sosial : 13 \\
\hline 2. & Pendanaan & a. Tahun 2017 : Rp 1.931.734.000 \\
& APBN & b. Tahun 2018: Rp 1.629.457.377 \\
\hline
\end{tabular}




\begin{tabular}{|c|c|c|}
\hline & & c. Tahun 2019 : Rp 1. 744.534.000. \\
\hline 3. & Sarana \& Prasarana & $\begin{array}{l}\text { a. Bangunan : } \\
\text { 1. } 3 \text { ruangan : kantor, kelas bimbingan sosial, dan kelas. } \\
\text { 2. Bangunan kokoh dan terawat } \\
\text { 3. Suasana nyaman, bersih, dan harum. } \\
\text { b. Kebutuhan Klien: } \\
\text { 1. Sandang } \\
\text { 2. Pangan }\end{array}$ \\
\hline 4. & $\begin{array}{lr}\text { Mekanisme } & \text { Pelayanan } \\
\text { Menggunakan } & \text { Metode } \\
\text { Pendekatan } & \\
\end{array}$ & $\begin{array}{l}\text { a. Pendekatan melalui bimbingan individu } \\
\text { b. Pendekatan melalui bimbingan kelompok }\end{array}$ \\
\hline 5. & Prosedur Pelayanan & $\begin{array}{l}\text { a. Assesmen sosial } \\
\text { b. Metode pendekatan } \\
\text { c. Bimbingan sosial } \\
\text { d. Bimbingan mental }\end{array}$ \\
\hline 6. & Faktor Pendukung & Program dan kegiatan tepat sasaran \\
\hline 7. & Faktor Penghambat & Kondisi warga binaan sulit diajak berkembang \\
\hline 8. & Kerjasama & $\begin{array}{l}\text { a. Internal: } \\
\text { 1. Pramu sosial } \\
\text { 2. Pejabat struktural lainnya. } \\
\text { b. Eksternal } \\
\text { 1. NPC (Non Playable Character) } \\
\text { 2. Bapeljamkesos } \\
\text { 3. Dinas Sosial DIY } \\
\text { 4. Kementerian Sosial RI }\end{array}$ \\
\hline 9. & Identitas Wawancara & $\begin{array}{l}\text { a. Kepala Pekerja Sosial : Ibu Titin (46th) } \\
\text { b. Sekretaris Pekerja Sosial : Mazda Tanjung (32th) }\end{array}$ \\
\hline & Kualitas Pelayanan & $\begin{array}{l}\text { Mengalami perkembangan dalam segi metode perkelompok } \\
\text { dan metode pendekatan individu sejak tahun } 2018 .\end{array}$ \\
\hline
\end{tabular}

\section{Pelayanan Rehabiltasi Sosial}

Bimbingan sosial untuk membantu seseorang agar mampu menyesuaikan diri dengan orang lain dengan keadaan lingkungan sosialnya. Bentuk bimbingan sosial meliputi metode individu dan metode kelompok.

a. Metode Individu

Bentuk bimbingan sosial dengan metode individu berupa pendampingan individual, activity daily living (ADL) dan pemantauan perkembangan aktivitas oleh petugas pekerja sosial. Bimbingan dengan metode individu terdapat Tiga (3) bimbingan antara lain:

1) Pemenuhan Kebutuhan Dasar (sandang dan pangan) Pemenuhan kebutuhan dasar yang meliputi sandang dan pangan disediakan oleh Balai Rehabilitasi Terpadu Penyandang Disabilitas dengan baik yaitu menyediakan makan sebanyak $3 x$ dalam sehari dan pemberian seragam bagi klien.

2) Bimbingan Activity of Day Living (ADL)

Bimbingan ADL dilakukan sebanyak lx dalam seminggu. Bimbingan ADL terdapat 2 kelompok yaitu ADL dasar dan ADL lanjutan. ADL dasar yaitu pelatihan kegiatan sehari-hari seperti, mandi, makan, dan membersihkan kamar. Selanjutnya terdapat ADL lanjutan yaitu aktivitas sosial yang berinteraksi dengan orang lain untuk membangun komunikasi dan kerjasama yang baik. Pelaksanaan ADL akan dilakukan selama fungsi sosialnya sudah berjalan dengan baik.

3) Bimbingan Orientasi Mobilitas (OM)

Bimbingan Orientasi Mobilitas dilakukan untuk penyandang disabilitas netra. Hal ini bertujuan agar disabilitas netra dapat berinteraksi dengan lingkungan dan mampu merasakan benda-benda sekitar. Pelaksanaan Orientasi Mobilitas dilakukan sebanyak $\mathrm{lx}$ dalam seminggu. Bimbingan orientasi mobilitas dibagi dalam 2 bimbingan yaitu teori dan praktik.

b. Metode Kelompok

Bimbingan kelompok yang dilakukan melalui pendampingan secara berkelompok dengan sistem bimbingan sosial. Bimbingan sosial dilakukan untuk membantu individu dalam kesatuan kelompok secara interaktif dan mampu bekerjasama dengan tim. Tujuan dari bimbingan sosial secara berkelompok adalah penyesuaian diri dalam lingkungan sosial dalam kehidupan bermasyarakat. Bimbingan dengan menerapkan metode kelompok terdapat beberapa bimbingan antara lain :

1) Bimbingan Agama

Melakukan peribadahan secara berjamaah di masjid bagi klien yang beragama muslim dan bagi klien yang beragama non muslim setiap sabtu dan minggu diperbolehkan pulang kerumah masing-masing untuk melakukan ibadah di gereja.

2) Bimbingan Pramuka

Bimbingan pramuka akan didapatkan oleh penyandang disabilitas dengan latar belakang disabilitas netra serta rahita dikarenakan disabilitas daksa dan rungu wicara tidak mampu mengeksplor banyak gerak. Tujuan dari bimbingan pramuka sendiri membentuk pola berfikir untuk hidup 
bersosial dengan lingkungan sosial berbeda-beda dan latar belakang yang dimiliki setiap warga binaan. Bimbingan pramuka selama tiga tahun terakhir ini, terhitung sejak tahun 2017-2019 terdapat beberapa perubahan-perubahan dalam kegiatan.

3) Bimbingan Olahraga

Bimbingan olahraga sasarannya yaitu seluruh warga binaan Balai Rehabilitasi Terpadu Penyandang Disabilitas Yogyakarta. Pelaksanaan bimbingan olahraga tidak terdapat pengembangan kegiatan maupun program terhitung sejak tiga tahun terakhir mulai dari tahun 2017-2019. Bimbingan olahraga terdapat 2 program yaitu kreasi dan prestasi. Program kreasi yaitu melakukan kegiatan senam bersama setiap hari jumat. Program prestasi melakukan kerjasama dengan Non Playable Character atau NPC. Non Playable Character atau NPC, adalah objek dalam game yang menggambarkan sebuah karakter seperti, manusia, hewan, robot dan lain-lain yang tidak dapat dikendalikan oleh player, namun dapat bertindak dan melakukan kegiatan yang seolah dikendalikan oleh player dan menghasilkan 9 medali dalam 3 tahun terakhir ini.

4) Bimbingan Kedisiplinan

Bimbingan kedisiplinan diajarkan kepada seluruh warga binaan tanpa terkecuali, meliputi : disabilitas netra, grahita, daksa dan rungu wicara. Pemberian materi mengenai bela negara, undang-undang, peraturan yang mengikat dalam tatanan masyarakat. Tujuan diadakannya kedisplinan ini untuk membiasakan anak agar taat peraturan karena segala sesuatu yang kita lakukan didasarkan hukum yang berlaku. Bimbingan kedisiplinan dalam 3 tahun terakhir tidak terjadi pengembangan program maupun kegiatan

\section{Faktor Penghambat dan Pendukung}

Faktor keberhasilan suatu pelayanan pada tahap Rehabilitasi sosial yaitu kegiatan-kegiatan yang dirasa sudah tepat sasaran dalam membentuk kepribadian dan mengembalikan fungsi sosialnya untuk bersosial di tengahtengah masyarakat.

Selain itu, terdapat faktor penghambat dalam mencapai tingkat keberhasilan antara lain, kondisi warga binaan yang tidak memungkinkan untuk dibimbing dan pola berfikir warga binaan yang tidak bisa diajak berkembang. Keterbatasan antara penyandang disabilitas satu dengan yang lainnya didasari oleh latar belakang dan kepribadian masing-masing dari warga binaan sosial.

\section{Rehabilitasi Medis}

Rehabilitasi medis ialah kegiatan pelayanan kesehatan yang melayani penderita gangguan fisik dan fungsi tubuh karena kondisi sakit atau cidera bertujuan untuk meningkatkan kemampuan fungsional dan kualitas hidup secara maksimal dengan menggunakan alat terapi fisik berdasarkan ilmu kedokteran fisik dan rehabilitasi medik.

Rehabilitasi medik menjadi bagian penting dalam proses rehabilitasi bagi penyandang disabilitas, karena sebagian dari mereka dapat dikembalikan fungsi bagian tubuhnya yang mengalami disabilitas atau minimal mengurangi kepada tingkat yang lebih parah. Berikut disajikan pada tabel 3. tentang data pelaksanaan rehabilitasi medis.

Tabel 3. Data Pelaksanaan Rehabilitasi Medis

\begin{tabular}{|c|c|c|}
\hline No & Point & Uraian \\
\hline 1. & Pekerja & $\begin{array}{l}\text { a. Dokter : } 2 \text { orang } \\
\text { b. Perawat : } 10 \\
\text { c. Pendukung perawat : } 3 \\
\text { d. Terapis fisioterapi : } 2 \\
\text { e. Terapis okupasi : } 1\end{array}$ \\
\hline 2. & Pendanaan APBN & $\begin{array}{l}\text { a. Tahun } 2017: \operatorname{Rp} 1.931 .734 .000 \\
\text { b. Tahun } 2018: \operatorname{Rp} 1.629 .457 .377 \\
\text { c. Tahun } 2019: \operatorname{Rp} 1.744 .534 .000 .\end{array}$ \\
\hline 3. & Sarana \& Prasarana & $\begin{array}{l}\text { a. Bangunan: } \\
\text { 1. Poliklinik dengan } 3 \text { bangsal } \\
\text { 2. Bangunan kokoh dan terawat } \\
\text { 3. Suasana nyaman, AC, bersih, dan harum. } \\
\text { b. Kebutuhan Obat: } \\
\text { 1. Obat nyeri kepala } \\
\text { 2. Paracetamol } \\
\text { 3. Amoxcilin, dll } \\
\text { c. Peralatan medis: } \\
\text { 1. Tensi } \\
\text { 2. Suntik } \\
\text { 3. Termometer } \\
\text { 4. Stetoskop } \\
\text { 5. Alat Infus, dll }\end{array}$ \\
\hline 4. & $\begin{array}{l}\text { Mekanisme Pelayanan } \\
\text { Medis }\end{array}$ & $\begin{array}{l}\text { a. Promotif } \\
\text { b. Preventif: }\end{array}$ \\
\hline
\end{tabular}




\begin{tabular}{|c|c|c|}
\hline & & $\begin{array}{l}\text { 1. Pemeriksaan Berkala } \\
\text { 2. Deteksi Dini Penyakit } \\
\text { d. Kuratif } \\
\text { e. Rehabilitatif: } \\
\text { 1. Pemulian Keadaan Pasca Sakit } \\
\text { 2. Latihan Fisik } \\
\text { 3. Istirahat } \\
\text { 4. Program Fisioterapi } \\
\text { 5. Program Okupasitherapy } \\
\text { 6. Program Hydrotherapy }\end{array}$ \\
\hline 5. & Prosedur Pelayanan & $\begin{array}{l}\text { a. Assesmen medis menghasilkan CFR/Rekam Medis } \\
\text { b. Mekanisme atau tahapan pelayan } \\
\text { c. Tindakan Medis }\end{array}$ \\
\hline 6. & Faktor Pendukung & Program dan kegiatan tepat sasaran \\
\hline 7. & Faktor Penghambat & Kondisi warga binaan parah dan sulit ditangani \\
\hline 8. & Kerjasama & $\begin{array}{l}\text { a. Internal: } \\
\text { 1. Pekerja medis secara keseluruhan } \\
\text { 2. Pejabat struktural lainnya. } \\
\text { b. Eksternal } \\
\text { 1. BPJS } \\
\text { 2. Bapeljamkesos } \\
\text { 3. Dinas Sosial DIY } \\
\text { 4. Kementerian Sosial RI } \\
\text { 5. Rumah Sakit : RS. Sardjito, RS. Panti Rapih, RS. } \\
\text { Bethesda }\end{array}$ \\
\hline 9. & Identitas Wawancara & $\begin{array}{l}\text { a. Kepala Sie Medis : Subakir, S.Sos (58thn) } \\
\text { b. Perawat: } \\
\text { 1. Nani Aryani (29th) } \\
\text { 2. Tatang (29th) } \\
\text { c. Pendukung Perawat : Fetty (35th) } \\
\text { d. Fisioterapi : Lukman (30th) } \\
\text { e. Okupasitherapi : Ulfa (28th) }\end{array}$ \\
\hline 10 & Kualitas Pelayanan & $\begin{array}{l}\text { Pengembangan Model dan Program: } \\
\text { 1. Program Okupasitherapy : Tahun } 2018 \\
\text { 2. Pojok PHBS dan Posyandis : Tahun } 2019 \\
\text { 3. Program RTL "Hydrotherapy" : Tahun } 2020\end{array}$ \\
\hline
\end{tabular}

Pelayanan Rehabilitasi Medis

Pelayanan rehabilitasi medis yang dilakukan BRTPD Dinas Sosial DIY meliputi pemantauan kesehatan bagi warga binaan baru sebelum menjadi klien di BRTPD Dinas Sosial DIY dan pemantauan kesehatan bagi klien di BRTPD. Adapun pelayanan rehabilitasi medis dibagi menjadi 4 yaitu:

a. Promotif

Promotif yaitu promosi kegiatan ditengah-tengah kegiatan yang dijalankan oleh medis. Demo yang dilakukan oleh pihak medis kepada warga binaan yaitu pengembangan model pada medis yang dijadikan sebagai program dan kegiatan pada bidang medis. Mengenalkan berbagai macam penyakit dan pertolongan pertama pada sakit yang di derita.

b. Preventif

Tindakan medis yang diambil sebelum menjalarnya penyakit. Selanjutnya, preventif dibagi dalam 2 tahap yaitu:

1) Pemeriksaan Berkala

Dilakukan untuk mencegah terjadinya kejadian buruk setelah didiagnosa bahwa pasien terjangkit penyakit. Biasanya pemeriksaan dilakukan sehari 3 kali dengan pengecekan secara rutin. Hal ini dilakukan untuk mencegah timbulnya penyakit lain maupun memburuknya penyakit yang diderita akibat tidak tertangani dengan baik.

2) Deteksi Penyakit

Deteksi dini penyakit sangat dianjurkan dalam tindakan medis karena untuk mengetahui tindakan apa yang cocok untuk menangani pasien dengan gejala penyakit A dan pasien dengan gejala penyakit B. Penyakit yang timbul di setiap pasien akan berbeda penanganannya dan pemberian obatnya karena disesuaikan dengan metabolisme dan daya tahan tubuh pasien.

c. Kuratif

Kuratif merupakan tahap tindak lanjut setelah pengecekan kesehatan, pemberian obat, dan perawatan. Adapun kegiatan yang menjadi bagian dari kuratif yaitu pelayanan rawat jalan untuk pasien yang telah dinyatakan sembuh dengan catatan masih dilakukan kontrol secara rutin. Penunjang kegiatan kuratif sendiri yaitu dengan dilaksanakannya pojok Perilaku Hidup Bersih dan Sehat (PHBS). Kegiatan pojok PHBS merupakan kegiatan yang bisa disebut sebagai konseling kondisi pasien atau warga binaan. Konseling dilakukan dengan pengecekan kesehatan lanjutan atau pelayanan rawat jalan untuk memastikan keadaan warga binaan dalam keadaan baik-baik saja. 


\section{d. Rehabilitatif}

Rehabilitatif merupakan tahap pengembalian pasien ke tengah-tengah masyarakat untuk menjalankan aktivitas sehari-hari dan mengembalikan fungsi sosialnya. Adapun tahapan rehabilitatif sebagai berikut:

1) Pemulihan Keadaan Pasca Sakit

Pemulihan keadaan dilakukan untuk mengembalikan semangat dan meningkatkan stamina diri agar mampu menjalani aktivtas sehari-hari. Pemulihan keadaan sakit bisa dilakukan dengan melakukan bimbingan jasmani dan bimbingan olahraga. Bimbingan itu terdiri dari senam, olahraga, dan kegiatan-kegiatan jasmani yang meningkatkan stamina.

2) Latihan Fisik Pasca Sakit Sebagai Pemulihan

Keadaan pasca sakit yang harus dipulihkan dengan memberikan kegiatan-kegiatan maupun latihan fisik yang menciptakan kebugaran untuk mengembalikan stamina dalam tubuh pasien. Latihan fisik dilakukan dengan bimbingan olahraga agar tubuh melakukan gerakan-gerakan untuk mengembalikan fungsi jasmaninya.

3) Istirahat dan Program Diet

Istirahat pasien harus dikontrol untuk mengembalikan secara penuh stamina dalam diri pasien. Selanjutnya, program diet bagi pasien yang mengalami gangguan obesitas untuk diatur pola makannya agar tidak menimbulkan penyakit akibat obesitas. Pengaturan pola makan didampingi oleh ahli gizi dengan melakukan penakaran kebutuhan asupan bagi warga binaan yang mengalami obesitas.

4) Program Fisioterapi

Program fisioterapi dilakukan untuk warga binaan dengan latar belakang cacat fisik atau tuna daksa. Program ini dijalankan untuk melatih gerak otot bagian tubuh yang tidak dapat digerakkan agar tidak terasa kaku dan dapat digerakan kembali. Fisioterapi dilakukan dengan cara penyinaran untuk menghangatkan otot agar lemas dan tidak kaku. Pelaksanaan fisioterapi di Balai Rehabilitasi Terpadu Penyandang Disabilitas selama 6 hari yaitu mulai hari senin-sabtu dengan waktu 6 jam mulai dari jam 8 pagi hingga jam 2 siang

5) Program Okupasi Therapy

Program Okupasi Therapy dilakukan apabila seseorang memiliki kecacatan ganda, seperti tuna grahita dengan tuna daksa, tuna grahita dengan down syndrom, dan tuna grahita dengan tuna netra. Okupasi Therapy merupakan suatu alternatif pengobatan yang berfokus kepada syaraf motorik dan sensorik anak. Mekanisme penanganan okupasi therapy lebih banyak pada pelatihan yang ditunjukan kepada anak celebral palsy, grahita, idiot dan kejang ringan. Pelaksanaan program Okupasi Therapy selama 4x dalam seminggu yaitu hari senin-kamis dengan waktu 8 jam mulai dari jam 8 pagi hingga jam 2 siang.

6) Progam Hydrotherapy

Program Hydrotherapy merupakan program baru di Balai Rehabilitasi Terpadu Penyandang Disabilitas Yogyakarta dengan metode air sebagai pengobatannya. Hydrotherapy sebagai alternatif pengobatan baru di dunia medis. Kebutuhan hydrotherapy yaitu kolam yang berisikan air. Metode ini mampu melatih syaraf sensorik untuk menciptakan gerak. Air yang digunakan juga kebanyakan adalah air asin yang dipercaya mampu melemaskan otot-otot yang kaku. Hydrotherpy baru memasuki tahap penjajakan pada tahun 2019 dan akan disahkan pada tahun 2020 sebagai pencapaian pengobatan alternatif metode air

\section{Faktor Penghambat dan Pendukung}

Faktor pendukung dalam memberikan pelayanan medis antara lain kerjasama tim antara pejabat fungsional secara internal dan pejabat fungsional secara eksternal terjalan dengan baik. Pelayanan medis tidak hanya dilakukan pada 1 instansi saja melainkan bekerjasama dengan instansi lain yaitu Bapeljamkesos dalam mencukupi kebutuhan warga binaan sosial. Sedangkan faktor penghambat dalam memberikan pelayanan medis diantaranya kesulitan dalam menjangkau rujukan karena posisi klinik yang ada di Balai Rehabilitasi Terpadu Penyandang Disabilitas merupakan bagian dari Dinas Sosial bukan bagian dari Dinas Kesehatan. Terkhusus pada regulasi perizinan rujukan kepada pihak atas yang sangat sulit untuk diakses.

\section{Bimbingan Keterampilan/Vokasional}

Bimbingan keterampilan atau vokasional merupakan program layanan yang diberikan kepada warga binaan sosial Balai Rehabilitasi Terpadu Penyandang Disabilitas dengan memberikan materi dan praktik keterampilan. Bimbingan keterampilan diharapkan mampu membentuk minat dan bakat warga binaan untuk bekal memasuki dunia kerja maupun menciptakan usaha mandiri. Berikut disajikan tabel 4 tentang data pelaksanaan rehabilitasi sosail.

Tabel 4. Daftar Bimbingan Keterampilan/Vokasional

\begin{tabular}{lll}
\hline No & \multicolumn{1}{c}{$\begin{array}{l}\text { Kenis } \\
\text { Keterampilan }\end{array}$} & Disabilitas \\
\hline 1. & Desain Grafis & Daksa dan Runguwicara \\
2. & Komputer & Daksa dan Runguwicara \\
3. & Menjahit & Daksa dan Runguwicara \\
4. & Elektronika & Daksa dan Runguwicara \\
5. & Massage/Pijat & Netra \\
6. & Kerajinan Sulam & Grahita \\
7. & Payet bordir & Grahita \\
\hline Sumber : Subbag TU BRTPD Yogyakarta, 2019
\end{tabular}

Pelaksanaan bimbingan keterampilan atau vokasional didukung atas sarana dan prasarana yang ada di Balai 
Rehabilitasi Terpadu Penyandang Disabilitas. Tak lupa terdapat pelaku atau penggerak terwujudnya bimbingan keterampilan agar berjalan dengan lancar. Adapun data yang diperoleh saat di lapangan dalam pelayanan keterampilan yang diberikan instruktur saat bimbingan vokasional dapat dilihat pada tabel 5 berikut:

Tabel 5. Data Pelaksanaan Bimbingan Keterampilan

\begin{tabular}{|c|c|c|}
\hline No & Point & Uraian \\
\hline 1. & Pekerja & $\begin{array}{l}\text { a. Instruktur Desain Grafis : } 1 \text { orang } \\
\text { b. Instruktur Komputer : } 1 \text { orang } \\
\text { c. Instruktur Elektro : } 1 \text { orang } \\
\text { d. Instruktur Menjahit : } 2 \text { orang } \\
\text { e. Instruktur Massage/Pijat : } 3 \text { orang } \\
\text { f. Instruktur Kerajinan Sulam : } 1 \text { orang } \\
\text { g. Instruktur Payet Bordir : } 1 \text { orang }\end{array}$ \\
\hline 2. & Pendanaan APBN & $\begin{array}{l}\text { a. Tahun } 2017: \text { Rp } 1.931 .734 .000 \\
\text { b. Tahun } 2018: \operatorname{Rp} 1.629 .457 .377 \\
\text { c. Tahun } 2019: \operatorname{Rp} 1.744 .534 .000\end{array}$ \\
\hline 3. & Sarana \& $\&$ Prasarana & $\begin{array}{l}\text { a. Bangunan: } \\
\text { 1. Ruang kelas keterampilan : } 8 \text { kelas } \\
\text { 2. Bangunan kokoh dan terawat } \\
\text { 3. Suasana nyaman, AC, bersih, dan harum. } \\
\text { b. Kebutuhan Keterampilan (alat dan bahan): } \\
\text { 1. Desain Grafis : Komputer (coral draw dan photoshop) } \\
\text { 2. Komputer : Komputer (software, hardware, e-commers) } \\
\text { 3. Menjahit : l. Bahan (kain, tile, dan spuring) } \\
\text { 2. Alat (gunting, jarum, benang, dan alat ukur ) } \\
\text { 4. Elektronik : mur, baut, obeng, kabel, listrik pararel, dll. } \\
\text { 5. Massage/Pijat (Sport, Sixte, Shiatsu): } \\
\text { 1. Bahan (minyak zaitun) } \\
\text { 2. Alat ( } 3 \text { tempat tidur) } \\
\text { 6. Kerajinan Sulam : l. Alat (gunting, ring, jarum) } \\
\text { 2. Bahan (Benang dan kain jadi) } \\
\text { 7. Payet Bordir : 1. Alat (gunting dan jarum) } \\
\text { 2. Bahan (payet bordir, lem tembal, dan Benang) }\end{array}$ \\
\hline 4. & MekanismeBimbinganVokasional & $\begin{array}{l}\text { a. Mendapatkan catatan sosial dan medis dari rehab sosial dan rehab } \\
\text { medis } \\
\text { b. Tindak lanjut memberikan bimbingan keterampilan sesuai dengan } \\
\text { kondisi dan kemampuan warga binaan. }\end{array}$ \\
\hline 5. & Prosedur Pelayanan & $\begin{array}{l}\text { a. Warga binaan mengikuti keterampilan sesuai dengan penentuan } \\
\text { dengan memperhatikan keadaan atau kondisi. } \\
\text { b. Mengikuti pembelajaran seminggu } 4 \mathrm{x} \text { yaitu hari senin-kamis dengan } \\
\text { waktu } 4 \text { jam mulai dari jam } 8 \text { pagi hingga } 11 \text { siang. } \\
\text { c. Bila sudah mahir mengikuti PBK }\end{array}$ \\
\hline & Faktor Pendukung & $\begin{array}{l}\text { Kemauan dan semangat dari warga binaan yang, selalu ingin terus } \\
\text { belajar }\end{array}$ \\
\hline & Faktor Penghambat & $\begin{array}{l}\text { Penerimaan klien baru dengan sistem buka tutup sehingga sulit } \\
\text { mengikuti perkembangan pembelajaran di setiap kelas vokasional. }\end{array}$ \\
\hline & Kerjasama & $\begin{array}{l}\text { a. Internal: } \\
\text { 1. Instruktur secara keseluruhan } \\
\text { 2. Pejabat struktural lainnya. } \\
\text { b. Eksternal: } \\
\text { 1. Perusahaan swasta terkait pemagangan/ PBK } \\
\text { 2. Pemilik usaha sesuai dengan keterampilan } \\
\text { 3. Dinas Sosial DIY } \\
\text { 4. Kementerian Sosial RI }\end{array}$ \\
\hline & Identitas Wawancara & $\begin{array}{l}\text { a. Instruktur Desain Grafis: Yakub (38th) } \\
\text { b. Instruktur Komputer: Barnas (44th) } \\
\text { c. Instruktur Elektro: Sunarto (72th) } \\
\text { d. Instruktur Menjahi: Dwi (58th) dan Suwarno (45th) } \\
\text { e. Instruktur Massage/Pijat: Heni (45th), Citra (38th), dan Ratih (30th) } \\
\text { f. Instruktur Kerajinan Sulam : Parmin (56th) }\end{array}$ \\
\hline
\end{tabular}


g. Instruktur Payet Bordir : Indah (36th)

10 Kualitas Pelayanan Pengembangan Model dan Program :

1. Tahun 2017 : (-) Perak

(-) Las

2. Tahun 2018 : (-) Kulit

(+) Revitalisasi Menjahit

3.Tahun 2020 : Program RTL "Bengkel Otomotif dan Home Industri”

Pelayanan Bimbingan Keterampilan/Vokasional

a. Disabilitas Netra

Bimbingan Vokasional bagi penyandang disabilitas netra adalah massage. Massage terdiri dari 3 macam yaitu, massage sport, massage sixte, dan massage shiatsu. Massage Sport, kelas dasar yang banyak mengajarkan teori-teori dasar. Melatih syaraf sensorik untuk merasakan titik-titik pemijatan agar tidak salah pijat. Massage Sixte, merupakan kelas 2 dalam serangkaian massage. Pelatihan-pelatihan yang diberikan sebagai lanjutan teori saat kelas dasar. Tindak lanjut dari teori kelas dasar berupa praktik pemijatan nyeri kepala, nyeri otot, nyeri haid, dll. Fokus praktik pada tahap massage sixte yaitu berfokus pada syaraf dalam. Massage shiatsu, merupakan kelas mahir dari seluruh serangkaian massage. Adapun materi dan praktik tambahan dalam kelas massage shiatsu yaitu teknik spa, akupuntur, dan pengobatan pijat alternatif. Masssage shiatsu menerapkan teknologi berbasis tiongkok dengan melakukan pemijatan pada titik-titik syarat utama.

b. Disabilitas Grahita

Bimbingan Vokasional yang diberikan untuk penyandang disabilitas grahita ialah sulam dan payet bordir. Keterbelakangan mental tidak dapat membuat pola pikir berkembang. Sehingga bimbingan vokasional hanya sebagai pengisi waktu kosong setelah pengobatan bagi disabilitas grahita. Fokus pelayanan bagi disabilitas grahita ialah pelayanan medis. Adapun bimbingan vokasional bagi tuna grahita dirangkum sebagai berikut :

1) Sulam, merupakan kegiatan yang diperuntukkan bagi tuna grahita untuk mengisi aktivits sehari-hari. Sulam yang dibentuk kebanyakan berpola bunga, kupu-kupu dan trigonometri. Hasil sulaman dari tuna grahita bisa berbentuk taplak meja, sapu tangan dan layer. Kegiatan menyulam dilakukan hanya 2 jam dalam sehari sebanyak 4x dalam seminggu yaitu hari senin-kamis. Adapun alat dan bahan yang dibutuhkan yaitu, gunting, jarum, ring, benang dan kain jadi.

2) Payet bordir, kelas payet bordir bagi tuna grahita yaitu payet bordir tempel dengan bermodalkan menjahit dan menempel bordiran yang sudah berbentuk. Hal ini dilakukan untuk mengisi waktu kosong bagi penyandang disabilitas grahita. Payet yang dijahit maupun ditempel kebanyakan berbentuk bunga. Kegiatan payet bordir dilakukan sebanyak $4 \mathrm{x}$ dalam seminggu dan waktu 2 jam dalam sehari. Adapun alat dan bahan yang dibutuhkan yaitu: gunting, jarum, lem tembak, payet border dan benang.

c. Disabilitas Daksa dan Rungu Wicara

Keterbatasan dalam gerak, mendengar, dan bicara mengkelompokkan disabilitas daksa dan ruwi masuk dalam kategori keterampilan yang menggunakan fikiran dan melatih untuk mengembangkan pola pikir, antara lain :
1) Desai Grafis

Bimbingan vokasional desain grafis ini berpusat pada keterampilan seseorang dalam mendesain melalui media komputer sebagai alat untuk mendesain. Materi desain yang diberikan kepada warga binaan sangat dasar dengan menggunakan aplikasi photoshop dan coral draw. Adapun tantangan yang dirasakan oleh warga binaan itu sendiri yaitu mengkontrol gerak tubuh yang berlebihan saat sedang mendesain karena nantinya akan menyebabkan hasil desain miring dan tidak lurus. Kebutuhan fasilitas untuk desain grafis sendiri terbilang cukup dan mendukung. Hanya saja terdapat beberapa kendala terkait ketersediaan komputer yang masih sedikit, idak seimbang dengan jumlah warga binaan yang mengikuti vokasional desain grafis.

2) Komputer

Bimbingan keterampilan komputer meliputi pemberian materi dasar seperti software, hardware, dan pemanfaatan e-commers. Pemberian materi software erupa pelatihan ms word, excel, dll. Bimbingan komputer dilakukan selama 4 hari dalam seminggu dengan jam operasional dari jam 8 pagi sampai jam 11 siang. Ketersediaan alat yaitu seperti komputer sejumlah 15 komputer, kabel data sebanyak 15, dan modul pembelajaran komputer. Adapun keluhan yang dirasakan instruktur yaitu terkait wifi dan proyektor. Bimbingan komputer tanpa proyektor dan wifi tidak bisa jalan sesuai dengan rencana.

3) Menjahit

Kelas menjahit merupakan kelas yang menciptakan suatu produk hasil dan banyak diminati oleh warga binaan. Jam operasional kelas menjahit yaitu setiap hari senin-kamis mulai jam 8 pagi hingga 11 siang dengan pemenuhan jadwal 16JPL/bulan. Adapun bahan yang dibutuhkan untuk kelas menjahit yaitu kain, kain tile, furing, dll. Produk hasil menjahit berupa dress, rok, celana, plisket, dll. Adapun alat yang dibutuhkan yaitu, mesin jahit, gunting, jarum, benang, alat ukur, penggaris dll. Tahapan kelas menjahit yaitu terdiri dari 2 yaitu kelas dasar dan kelas mahir. Kelas mahir terdiri dari beberapa warga binaan yang dirasa memiliki bakat beda dari yang lainnya dan sudah mahir dalam menjahit. Selanjutnya, bagi warga yang ingin mengikuti Praktik Belajar Kerja atau PBK harus melewati tahapan di kelas mahir terlebih dahulu.

4) Elektronika

Bimbingan elektronik merupakan bimbingan yang mengajarkan tentang listrik dan tegangan listrik serta arus listrik. Bimbingan ini merupakan suatu bimbingan yang didominasi oleh warga binaan berjenis kelamin laki-laki. Bimbingan elektronik dituntut untuk bisa menghasilkan produk dengan penyusunan pararel listrik. Ketersediaan bahan yaitu meliputi pararel 
listrik, mur, baut, dan kabel. Selanjutnya, alat yang disedikan yaitu tang, obeng, dan berbagai macam kunci. Produk hasil elektronika yaitu berupa : perbaikan sound system, perbaikan televisi, perbaikan radio, dan segala bentuk perbaikan alat elektronik. Materi yang diberikan pada bimbingan ini berupa materi penyusunan paralel listrik, arus listrik dan tegangan listrik.

\section{Faktor Penghambat dan Pendukung}

Faktor pendukung dalam memberikan bimbingan keterampilan berwujud kerjasama antara pejabat fungsional satu dengan pejabat fungsional lainnya. Disamping itu, komunikasi antara instruktur dengan warga binaan harus berjalan dengan semestinya dan baik agar menciptakan pelayanan yang mengalir dan tepat pada sasaran. Selanjutnya, terdapat faktor penghambat dalam memberikan pelayanan yaitu, dalam proses mengajar terkendala dengan fasilitas yang sedikit kurang lengkap karena pada dasarnya sistem penerimaan terbuka dan tertutup sehingga banyak warga binaan yang baru masuk terlambat menerima materi dan harus menyesuaikan dengan warga binaan lainnya yang lebih dulu masuk bimbingan keterampilan. Para instruktur dalam mengajar merasa kesulitan akibat harus mengulang materi secara terus menerus satu persatu karena keterbatasan tidak ada proyektor untuk menunjang belajar mengajar.

\section{KESIMPULAN}

Balai Rehabilitasi Terpadu Penyandang Disabilitas merupakan Unit Pelayanan Terpadu Daerah dalam naungan Dinas Sosial DIY yang menampung warga binaan berjumlah 185 orang. Warga binaan sosial yang diperbolehkan mengikuti serangkaian rehabilitasi di Balai Rehabilitasi Terpadu Penyandang Disabilitas merupakan warga berdomisili di Daerah Istimewa Yogyakarta ditunjukkan sesuai dengan Kartu Tanda Penduduk (KTP). Syarat khusus untuk menjadi warga binaan sosial di Balai Rehabilitasi Terpadu Penyandang Disabilitas yaitu seseorang yang memiliki keterbatasan khusus atau peyandang disabilitas dengan tujuh kategori yaitu : tuna netra, tuna grahita, tuna daksa, tuna rungu, tuna wicara, down syndrome dan idiot.

Pelayanan yang diberikan di Balai Rehabilitasi Terpadu Penyandang Disabilitas memiliki tahapan pelayanan dimulai dari rehabilitasi sosial, rehabilitasi medis dan bimbingan keterampilan atau vokasional. Ketiga tahapan diatas merupakan serangkaian rehabilitasi yang harus dijalankan oleh warga binaan. Selama 3 tahun terakhir serangkaian rehabilitasi mengalami peningkatan dan tidak menutup kemungkinan juga terjadi kendala dalam pencapainnya. Kendala yang sering terjadi yaitu sulitnya komunikasi dengan warga binaan dikarenakan sistem pendaftaran buka tutup sehingga bagi warga binaan baru merasa tertinggal. Meskipun sistem pendaftaran buka tutup tidak membuat Balai jauh tertinggal dan bisa dibuktikan oleh lulusan Balai Rehabilitasi Terpadu Penyandang Disabilitas mampu bekerja bersaing dengan banyak orang dan interaksi sosial terjalin didalamnya

\section{REFERENSI}

Andayani, A., \& Afandi, M. (2016). Pemberdayaan dan Pendampingan Komunitas Penyandang Disabilitas Dalam Mengakses Pendidikan Tinggi. APLIKASIA: Jurnal Aplikasi
Ilmu-Ilmu Agama, 16(2),

https://doi.org/10.14421/aplikasia.vl6i2.1178

Dewi, U. (2015). IMPLEMENTASI KEBIJAKAN KUOTA BAGI PENYANDANG DISABILITAS UNTUK MENDAPATKAN PEKERJAAN DI KOTA YOGYAKARTA. NATAPRAJA: Kajian Ilmu Administrasi Negara, 3(2). https://doi.org/10.21831/jnp.v3i2.11969

Halalia, M. R. (2017). Pemenuhan Hak Politik Penyandang Disabilitas Sesuai Dengan Undang-Undang Nomor 8 Tahun 2016 Tentang Penyandang Disabilitas Oleh Komisi Pemilihan Umum (KPU) Kota Yogyakarta. SUPREMASI HUKUM, 6(2), 1-24.

Holle, E. S. (2011). PELAYANAN PUBLIK MELALUI ELECTRONIC GOVERNMENT: UPAYA MEMINIMALISIR PRAKTEK MALADMINISTRASI DALAM MENINGKATAN PUBLIC SERVICE. SASI, 17(3), 21. https://doi.org/10.47268/sasi.vl7i3.362

Indriyany, I. A. (2015). Pelayanan Publik dan Pemenuhan Hak Difabe: Studi tentang Layanan Pendidikan Inklusif Melalui Kasus Pemindahan Difabel dari Sekolah Reguler ke Sekolah Luar Biasa di Yogyakarta. INKLUSI, 2(1), 1. https://doi.org/10.14421/ijds.020109

Mumpuni, S. D., \& Zainudin, A. (2017). AKSESBILITAS PENYANDANG DISABILITAS DALAM PELAYANAN PUBLIK DI KABUPATEN TEGAL. Jurnal Komunikasi Pendidikan, 1(2). https://doi.org/10.32585/jkp.vli2.24

Pratomo, D. T. (2015). Pelaksanaan Perlindungan Hak Atas Pendidikan bagi Penyandang Disabilitas (People With Disability) di Universitas Negeri Gorontalo. Jurnal Hukum, 3(2).

http:/hukum.studentjournal.ub.ac.id/index.php/hukum/iss ue/view/36

Sugiyono. (2009). Metode Penelitian Kuantitatif, Kualitatif dan Re D. Alfabeta.

Sugiyono. (2012). Metode Penelitian Pendidikan Pendekatan Kuantitatif, Kualitatif Dan Re $\mho D$. Alfabeta.

Tanjung, M. (2018). Dampak Pemberian Bantuan Stimulan Terhadap Pemberdayaan Ekonomi Penyandang Disabilitas Alumni Balai Rehabilitasi Terpadu Penyandang Disabilitas Yogyakarta Perspektif Maqāşid Syarī ah. UII Press.

Thohari, S. (2014). Pandangan Disabilitas dan Aksesibilitas Fasilitas Publik bagi Penyandang Disabilitas di Kota Malang. IJDS : Indonesian Journal of Disabilities Studies, 1(1), 2734.

Yunizar, D. K. (2015). STUDI ERGONOMI PADA AKSESIBILITAS DIFABLE PUSKESMAS DEPOK I SLEMAN; STUDI KASUS PUSKEMAS DEPOK I SLEMAN. Jurnal Arsitektur KOMPOSISI, 11(1), 21. https://doi.org/10.24002/jars.vllil.1103 